\title{
Statistical features of seismoelectric signals prior to M7.4 Guerrero-Oaxaca earthquake (México)
}

\author{
A. Ramírez-Rojas ${ }^{1}$, E. L. Flores-Márquez ${ }^{2}$, L. Guzmán-Vargas ${ }^{3}$, G. Gálvez-Coyt ${ }^{4}$, L. Telesca ${ }^{5}$, and F. Angulo-Brown ${ }^{6}$ \\ ${ }^{1}$ Área de Física de Procesos Irreversibles, Universidad Autónoma Metropolitana Azcapotzalco, Avenida San Pablo 180 \\ Colonia Reynosa, Azcapotzalco, 02200, México D. F., México \\ ${ }^{2}$ Inst. de Geofísica, UNAM, Circuito Exterior S/N, Cd. Universitaria, 04510 México D. F., México \\ ${ }^{3}$ Unidad Profesional Interdisciplinaria en Ingeniería y Tecnologías Avanzadas, Inst. Politécnico Nacional, \\ 07738, México D. F., México \\ ${ }^{4}$ Dep. de Matemáticas, Unidad Profesional Interdisciplinaria de Biotecnología del Inst. Politécnico Nacional, \\ Av. Acueducto S/N, Col. Barrio La Laguna Ticomán, C. P. 07340, México D. F., México \\ ${ }^{5}$ Inst. di Metodologie per l'Analisi Ambientale, Consiglio Nazionale delle Ricerche, C. da S. Loja, 85050 Tito (PZ), Italy \\ ${ }^{6}$ Dep. de Física, Escuela Superior de Física y Matemáticas, Inst. Politécnico Nacional, Edif. 9, U. P. Zacatenco, \\ 07738, México D. F., México
}

Received: 9 July 2008 - Revised: 20 August 2008 - Accepted: 25 August 2008 - Published: 12 September 2008

\begin{abstract}
In this paper a statistical analysis of seismoelectric ULF signals prior to the M7.4 Guerrero-Oaxaca earthquake (EQ) occurred at the Mexican Pacific coast on 14 September 1995, has been performed. The signals were simultaneously recorded at three monitoring stations from the last months of 1994 until July of 1996. The nonlinear time series methods of Higuchi fractal dimension (HFD) and detrended fluctuation analysis (DFA) have been used. In the three data sets we found some complex dynamical behaviors that seemingly reflect a relaxation-EQ preparation-main shock-relaxation process. In particular, clear spike-like anomalies in both DFAand HFD-exponents some months before the main shock are revealed.
\end{abstract}

\section{Introduction}

The comprehensive study of the final rupture of a heterogeneous material has shown that some physical phenomena as ULF electromagnetic and acoustic emissions take place along with this process (Hayakawa, 2001; Hayakawa et al., 2004). This is the case of the crust fracture mechanism accompanying earthquake (EQ) occurrences. Many studies have been focused on fractal and multifractal properties of geolectric signals in order to reveal possible electromagnetic precursors of EQ with significant magnitude (Varotsos et al.,

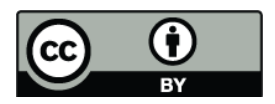

Correspondence to: A. Ramírez-Rojas (arr@ correo.azc.uam.mx)
1996, 2002, 2003; Eftaxias et al., 2004; Hayakawa et al., 1999, 2000; Hayakawa and Timashev, 2006; Smirnova et al., 2001; Telesca et al., 2001, 2003, 2005a, 2005b, 2007; Ida et al., 2005; Ida and Hayakawa, 2006; Ida et al., 2007; Gotoh, 2004; Smirnova, 2004). Furthermore, the presence of precursory signatures of EQs has been clearly identified in the ULF range for large magnitude (Ms $>6$ ) EQ's (Fraser-Smith et al., 1990; Molchanov et al., 1992; Kopytenko et al., 1993, Hayakawa et al., 1996; Flores-Marquez et al., 2007). In a previous work we performed a statistical analysis of the spectral exponent and the correlation time of geoelectrical signals associated to the Guerrero-Oaxaca EQ (Ms=7.4) occurred on 14 September 1995 in southern Mexico (Ramirez-Rojas et al., 2004). The South Pacific Mexican coast is a very seismically active region linked to the border of the Cocos and the American tectonic plates. This border is known as the Middle American Trench. Some years ago several electroseismic stations near this region (Yépez et al., 1995) were installed following the so-called VAN-methodology (Varotsos and Alexopoulos, 1984a, b). In particular, the aforementioned EQ was studied by using electric signals recorded at Acapulco station $\left(16.85^{\circ} \mathrm{N}, 99^{\circ} \mathrm{W}\right)$ during the last months of 1994 and approximately the whole year 1995. Furthermore, during this period ULF-geoelectrical data were measured by other two stations located at Coyuca $\left(17.35^{\circ} \mathrm{N}, 100.7^{\circ} \mathrm{W}\right)$ and Ometepec $\left(16.4^{\circ} \mathrm{N}, 98.13^{\circ} \mathrm{W}\right)$, respectively. The distance between the Ms=7.4 epicenter $\left(16.31^{\circ} \mathrm{N}, 98.88^{\circ} \mathrm{W}\right)$ and Acapulco, Coyuca and Ometepec stations was $110 \mathrm{~km}$, $200 \mathrm{~km}$ and $50 \mathrm{~km}$ respectively (Fig. 1). In Ramirez-Rojas et al. (2004) it was found that for Acapulco data, the power

Published by Copernicus Publications on behalf of the European Geosciences Union. 


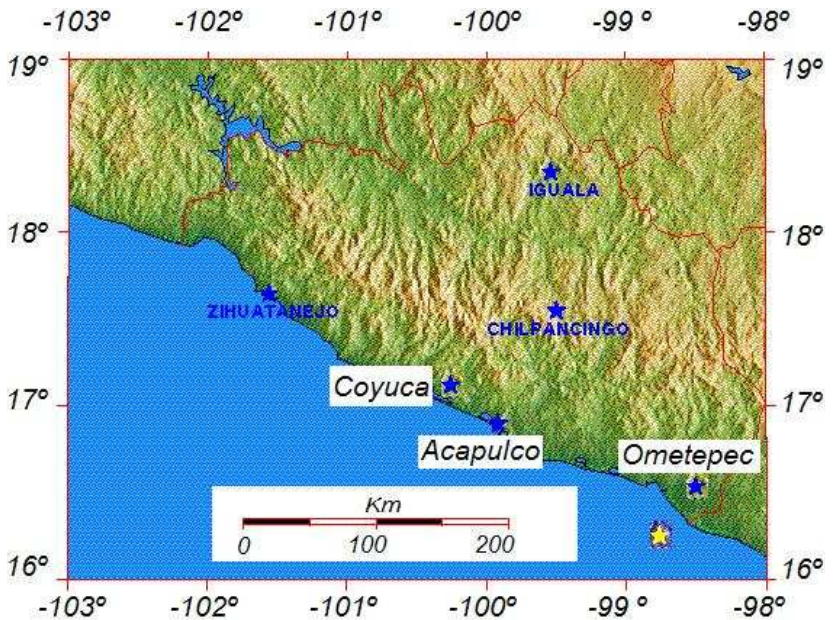

Fig. 1. Location of the three monitoring stations and the epicenter of the Ms=7.4 EQ (star).

spectrum showed a crossover behavior, with a low frequency range of the signals $(0.002 \mathrm{~Hz}-0.01 \mathrm{~Hz})$ characterized by a white noise behavior, while high frequencies $(0.01 \mathrm{~Hz}-$ $0.25 \mathrm{~Hz}$ ) exhibited a complex correlated behavior. Similar results were observed for the correlation times (Ramirez-Rojas et al., 2004) of the same data. In the present paper, we analyze the Acapulco, Coyuca and Omepetec geoelectrical data by using two different methods: the Detrended Fluctuation Analysis (DFA) and the Higuchi's fractal dimension (HFD). Our results from the three stations reveal important changes in the fractal organization probably related to the aforementioned EQ. The paper is organized as follows: in Sect. 2 a brief description of DFA and HFD is given; in Sect. 3 the data set is described. The results and their discussion are presented in Sect. 4; in Sect. 5 the concluding remarks are given.

\section{Methods: Detrended Fluctuation Analysis and Higuchi's fractal dimension.}

The Detrended Fluctuation Analysis (DFA) method introduced by Peng et al. (1994, 1995) has been used to detect long-term correlations in nonstationary time series. The original time series is first integrated. Next, the integrated time series is divided into boxes of equal length, $n$. For each box, a linear regression fit (representing the trend in that box) is performed. The $y$ coordinate of the fitting line is denoted by $y_{n}(k)$.

Next, the integrated time series, $y(k)$, is detrended by subtracting the local trend, $y_{n}(k)$. The root-mean-square fluctuation of this integrated and detrended time series is calculated by
$F(n)=\sqrt{\frac{1}{N} \sum_{k=1}^{N}\left[y(k)-y_{n}(k)\right]^{2}}$

This computation is repeated over all time scales (box sizes) to characterize the relationship between $F(n)$, the average fluctuation, and the box size, $n$.

Typically, $F(n)$ will increase with the box size. A linear relationship on a log-log plot indicates the presence of power law scaling:

$F(n) \sim n^{a}$

Under such conditions, the fluctuations can be characterized by the scaling exponent. The value of the scaling exponent characterizes the correlation in the time series. For example, white noise is characterized by $\alpha=0.5$. Another two special cases are: $\alpha=1$ corresponding to long-term correlated noise ( $1 / f$ noise) and $\alpha=1.5$, a Brownian noise. When the scaling exponent is within the interval $0.5<\alpha<1$, indicates persistent long-range power-law correlations. In contrast, $0<\alpha<0.5$ indicates a different type of power-law correlation such that large and small values of the time series are more likely to alternate. Our calculations were performed with windows of 3-h (2700 data points for Coyuca and Ometepec and 5400 data points for Acapulco).

The Higuchi's method (1988) was proposed to estimate the fractal dimension of nonstationary time series. One of the advantages of the Higuchi's fractal dimension (HFD) is that it gives stable indices even for a small number of data. Higuchi $(1988,1990)$ considers a finite set of time series of length $N$, taken at a regular interval: $x(1), x(2), x(3), \ldots$, $x(N)$. From the original time series, a new time series, $x_{m}^{k}$ is obtained and defined as follows:

$x_{m}^{k}: x m, x(m+k), x(m+2 k), \ldots, x\left(m+\left[\frac{N-k}{k}\right] k\right)$

where $m=1,2, \ldots, k$, and [ ] denotes the Gauss's notation. Here $m$ and $k$ are integers that indicate the initial time and the time interval respectively. For a time interval equal to $k$, one gets $k$ sets of new time series. Higuchi defines (1988) the length of the curve associated to each time series $x_{m}^{k}$ as follows:

$L_{m}^{k}=\sum_{i=1}^{\left[\frac{N-k}{k}\right]}[x(m+i k)-x(m+(i-1) k)]\left(\frac{N-1}{\left[\frac{N-k}{k}\right] k}\right) \frac{1}{k}$

where the term $\frac{N-1}{\left[\frac{N-k}{k}\right] k}$ is a normalization factor. The length of the curve for the time interval $k$ is taken as the average value $<L(k)>$ over $k$ sets of $L_{m}(k)$. If the average value obeys the scaling law:

$<L(k)>\sim k^{-D}$

then the curve is fractal with dimension D (Higuchi, 1988). 


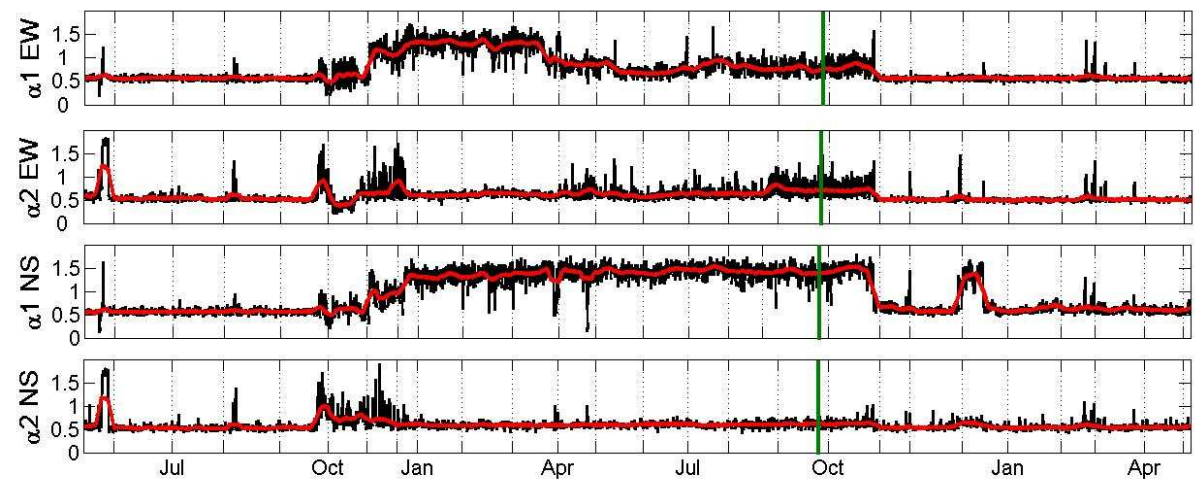

Fig. 2. Time evolution of DFA-exponents $(\alpha 1$ and $\alpha 2)$ for NS and EW Acapulco data. The monitoring period is from June 1994 to July 1996. The EQ is marked with a vertical green line.

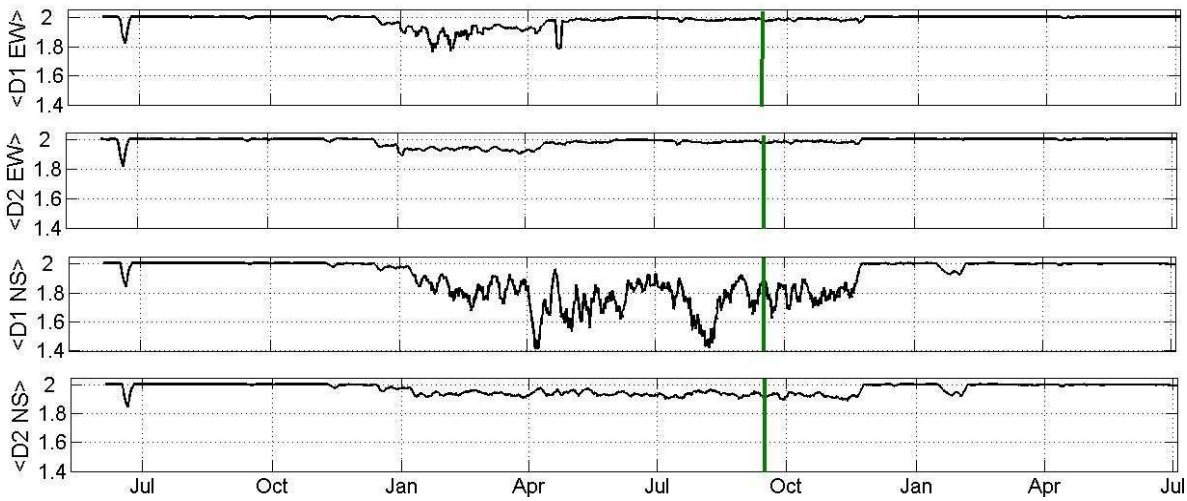

Fig. 3. Time evolution of Higuchi's fractal dimension (D1 and D2) for NS and EW Acapulco data. In this case, the exponents are the result of a moving average for windows of 25 points. The monitoring period is from June 1994 to July 1996. The EQ is marked with a vertical green line.

\section{Data}

The three monitoring electroseismic stations were located in Acapulco $\left(16.85^{\circ} \mathrm{N}, 99^{\circ} \mathrm{W}\right)$, Coyuca $\left(17.35^{\circ} \mathrm{N}, 100.7^{\circ} \mathrm{W}\right)$ and Ometepec $\left(16.4^{\circ} \mathrm{N}, 98.13^{\circ} \mathrm{W}\right)$, all of them situated in the south of Mexican Pacific coast, which is one of the most important seismic regions in Mexico (Fig. 1). At each electroseismic station two self-potential time series were simultaneously recorded, between two electrodes buried $2 \mathrm{~m}$ into the ground and separated by a distance of $50 \mathrm{~m}$. A couple of electrodes was oriented in North-South direction (NS channel), and other one in East-West direction (EW channel). Two different sampling rates were used: $\Delta \mathrm{t}=4 \mathrm{~s}$ in Coyuca and Ometepec stations, and $\Delta \mathrm{t}=2 \mathrm{~s}$ in Acapulco station (Yepez et al., 1995). The experimental equipment was based on the VAN methodology (Varotsos and Alexopoulos, 1984a, b). Almost all the time series monitored were continuous, nevertheless short lacks of data in Ometepec and Coyuca data sets were present. In Acapulco station the electric signal was recorded from June 1994 until July 1996 and, at Ometepec and Coyuca stations from November 1994 to July 1996.

\section{Results and discussion}

In the present paper we analyzed the dynamical behavior of both: low frequency $(0.002 \mathrm{~Hz}-0.01 \mathrm{~Hz})$ and high frequency $(0.01 \mathrm{~Hz}-0.25 \mathrm{~Hz})$ ranges of signals measured at Acapulco station during the observation period from 1994 to 1996. Figure 2 shows the time variation of the DFA-exponents $\alpha_{1}$ and $\alpha_{2}$ corresponding to high and low frequencies, respectively. The average value $\left\langle\alpha_{2}>\sim 0.5\right.$ for both NS and EW channels, indicates a white noise behavior; while $\left\langle\alpha_{1}>\right.$ shows a complex behavior characterized by a significant increment of its value approximately one year before the occurrence of the Guerrero-Oaxaca EQ. In particular, for the period from April to October 1995, we observe that $<\alpha_{1}>\sim 1$ for EW channel, indicating the presence of long-range correlation. Figure 3 shows the time variation of Higuchi's fractal dimensions $D_{1}$ and $\mathrm{D}_{2}$, corresponding to the short (high frequency) and large (low frequency) time scales (ranges): their temporal patterns are very similar to those shown by the DFA-exponents. We remark that the large ULF anomaly lasting for more than sixty days observed at this station, by means of DFA and 


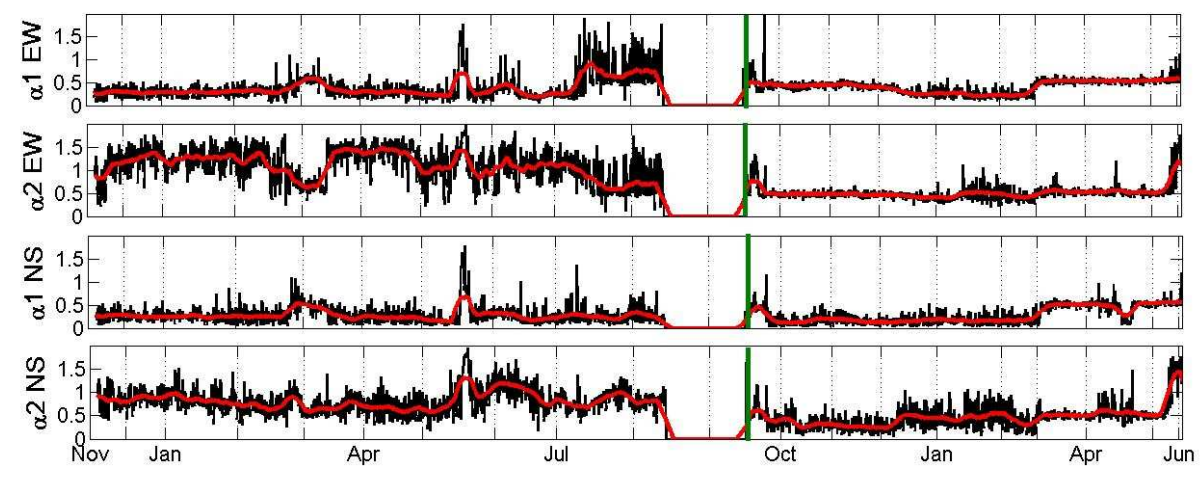

Fig. 4. Time evolution of DFA-exponents $(\alpha 1$ and $\alpha 2)$ for NS and EW Omepetec data. The monitoring period is from November 1994 to July 1996. The EQ is marked with a vertical green line.

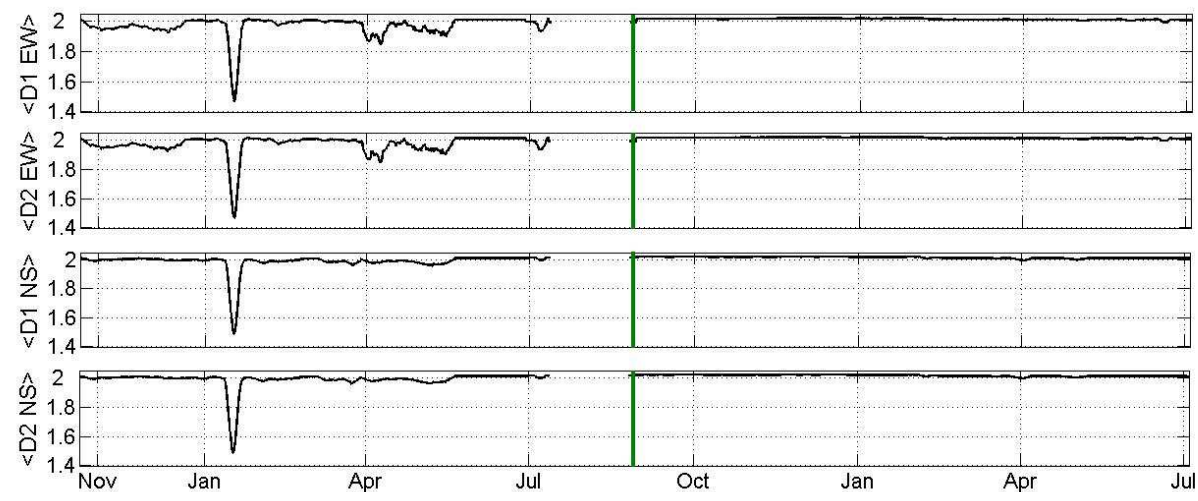

Fig. 5. Time evolution of Higuchi's fractal dimension (D1 and D2) for NS and EW Omepetec data. The monitoring period is from November 1994 to July 1996. The EQ is marked with a vertical green line.

HFD methods, is probably related to EQ preparation mechanism. Notice that Acapulco station is located $110 \mathrm{~km}$ from the main shock epicenter. This observation is within the empirical threshold $0.025 \mathrm{R} \leq \mathrm{M}-4.5$ given by Hayakawa et al. (2007) for ULF geomagnetic signals, here $\mathrm{R}$ is the distance between the station and the epicenter and $\mathrm{M}$ is the EQ magnitude. We also remark that this kind of large anomalies has been reported for geoelectrical signal changes (during 56 days) for an M6.6EQ in Japan (Uyeda et al., 2000).

Figures 4 and 5 show the DFA and HFD results for Omepetec (the nearest station to the EQ epicenter) data. Unfortunately this station presents a lack of data (45 days before the main shock). The analysis of the time variation of the two DFA-exponents $\alpha_{1}$ and $\alpha_{2}$ reveals a white noise dynamics $\left(<\alpha_{1}>\sim 0.5\right)$ and a complex behavior $\left(<\alpha_{2}>\sim 1\right)$ respectively. In particular, $<\alpha_{2}>\sim 1$ indicates the existence of $1 / f$-type long range correlations at large timescales, after the main shock, $\left\langle\alpha_{2}>\right.$ fluctuates around the average value 0.5 . This value, which is typical of white noise dynamics, can suggest the onset of a relaxation process.

Figures 6 and 7 show the DFA and HFD results for the Coyuca ULF-geoelectrical data. Nevertheless, this station is the farthest one from the epicenter, it has been suggested that under certain favorable conditions some geoelectric anomalies can be observed at such distances (Bernard, 1992). The time variation of $\left\langle\alpha_{1}\right\rangle$ indicates a white noise dynamics at low timescales, while the temporal evolution of $<\alpha_{2}>$ shows an increment in April 1995 in both NS and EW channels. In particular, the increment observed in $\alpha_{2}$ - variation of the EW time series is the largest one. The time variation of the Higuchi's fractal dimensions $\mathrm{D}_{1}$ and $\mathrm{D}_{2}$ shows a significant decrement in April 1995.

It is striking to note the concomitant anomalous behavior in Ometepec and Coyuca data almost five months before the occurrence of the EQ in the time variation of $\alpha_{1}, \alpha_{2}$, D1 and D2 in both NS and EW channels. However, at the beginning of January we observed a noticeable peak in all the HDF exponents in Ometepec station which is not present in DFA behavior. The problem of possible correlations between the fluctuation of spectral exponent or related quantities with seismicity has been already studied in Smirnova et al. (2001) and Hayakawa et al. (1999, 2000). It was revealed that the spectrum of ULF-geomagnetic field exhibits a power law $S(f) \propto f^{-\beta}$, where $\beta$ runs over a range corresponding to fractional Brownian motion. Varotsos et al. $(2002,2003)$ studied the correlation properties of seismic electric signals 


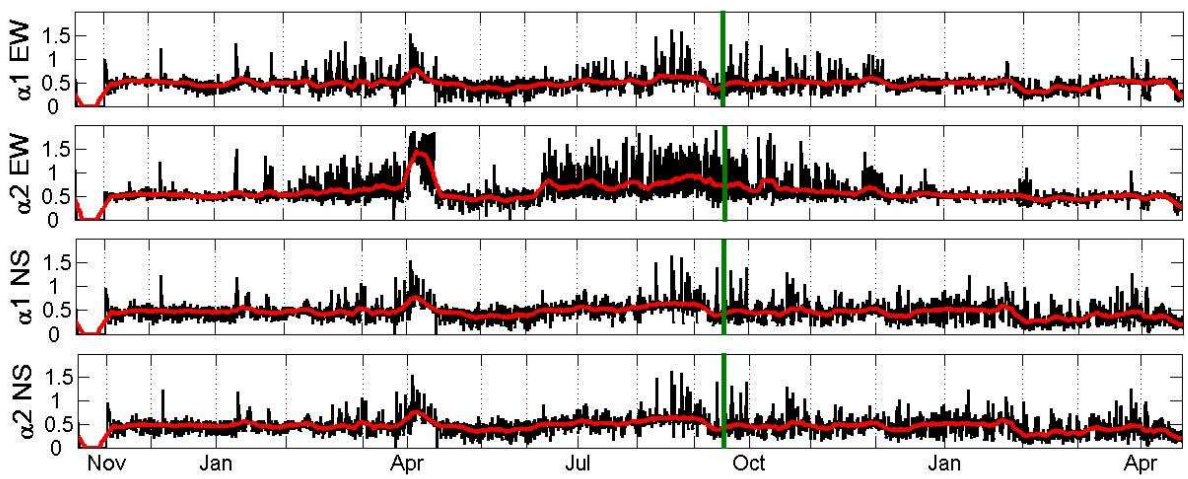

Fig. 6. Time evolution of DFA-exponents ( $\alpha 1$ and $\alpha 2)$ for NS and EW Coyuca data. The monitoring period is from November 1994 to July 1996. The EQ is marked with a vertical green line.

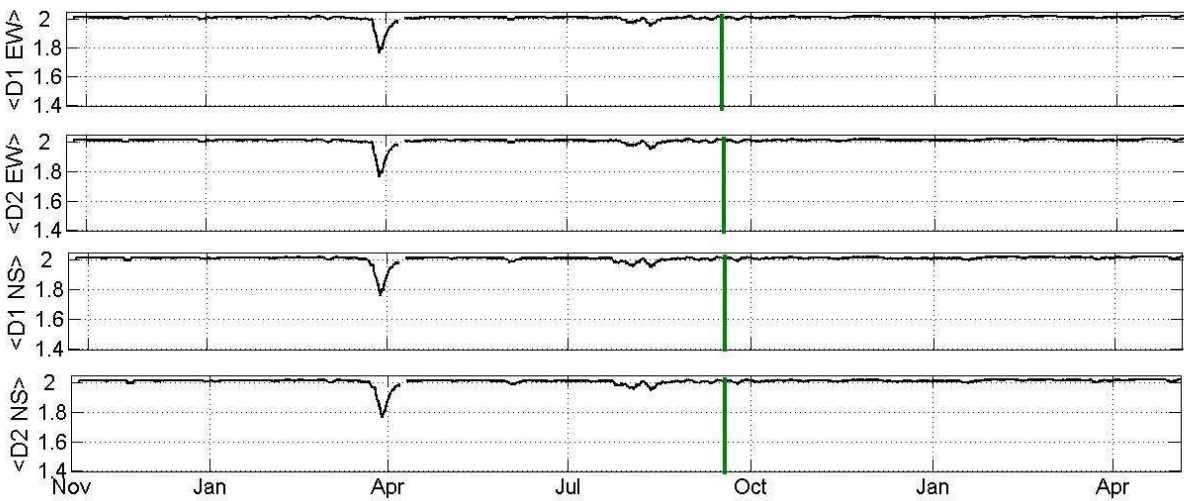

Fig. 7. Time evolution of Higuchi's fractal dimension (D1 and D2) for NS and EW Coyuca data. The monitoring period is from November 1994 to July 1996. The EQ is marked with a vertical green line. The crossover was less evident in Coyuca HFD-exponents.

(SES), monitored in Greece and Japan, by using the rescaled range analysis, finding that SES displays long-range correlations before the occurrence of large EQs. Ramirez-Rojas et al. (2004) showed the presence of a crossover frequency in Acapulco data, $f_{c} \approx 0.01 \mathrm{~Hz}$, with different dynamical behaviors for small and large frequencies before the occurrence of the Guerrero-Oaxaca EQ.

We observe a possible mechanism of relaxationpreparation-main shock-relaxation process, which was also suggested by Varotsos (2005) for data collected in Greece. That is, before an earthquake the stress (pressure) gradually varies in the focal area affecting several physical properties, like the static dielectric constant (Varotsos, 1978; Varotsos, 1980), the conductivity (Kostopoulos et al., 1975; Varotsos and Alexopoulos, 1980) etc. Furthermore, this stress variation may change the relaxation time for the orientation of the electric dipoles formed, due to lattice defects (Lazaridou et al., 1985). It may happen that, when the stress (pressure) reaches a critical value, these electric dipoles exhibit a cooperative orientation (collective orientation), thus leading to emission of transient electric signals termed Seismic Electric Signals, SES (Varotsos and Alexopoulos, 1984b). Hence, since criticality is always associated with fractality, it is expected that precursory electric signals should exhibit fractal properties (Varotsos, 2005), such as we observed for the Guerrero-Oaxaca EQ.

This mechanism is strongly related to the time variation of the DFA exponents and Higuchi fractal dimensions analyzed in the present study. It is remarkable that both Coyuca and Ometepec data present a peak in the $\alpha$-exponents around April-May 1995, approximately five months before the main-shock. Lead times of long duration have been also reported before EQ's of M>6 in Japan (Uyeda et al., 2000). This peak is less evident in Acapulco data, probably because it is embedded in a wider geoelectrical anomaly. A similar peak is very clear in $D_{1}$ and $D_{2}$ variations for Coyuca time series, although less evident in Omepetec and Acapulco data. In summary, the Guerrero-Oaxaca EQ seemingly had ULFgeoelectrical precursors in the frequency band $(0.01,0.25)$ $\mathrm{Hz}$, observed simultaneously in the three monitoring stations and both channels. 


\section{Concluding remarks}

In this paper we have analyzed the dynamical behavior of ULF-geoelectrical signals recorded in three monitoring stations located along the Pacific coast of Guerrero state in Mexico. These signals were measured during several months before and after the strong Ms=7.4EQ occurred on 14 September 1995. All the data present a crossover phenomenon, with a crossover frequency around $0.01 \mathrm{~Hz}$. A spike-like behavior is observed in the time variation of $\alpha$-exponents around April-May 1995, approximately five months before the main-shock, particularly evident in Coyuca and Ometepec data. Similar behavior has been revealed by the time variation of $D_{1}$ and $D_{2}$ especially for Coyuca data. Our conclusion is that these parameters, describing the dynamics of ULF geoelectrical data can be considered as good candidates to precursors of the Guerrero-Oaxaca EQ occurred in September 1995. On the other hand, although the possible geoelectric precursors suggested by us seem to be significant, they lack of isotropy just, as it was reported by Yonaiguchi et al. (2007), for VHF electromagnetic emissions in Japan.

Acknowledgements. We thank C. G. Pavia-Miller for providing us some geoelectric data. FAB and LGV thanks partial support from EDI-COFAA-IPN and ARR thanks partial support from AFPI-CB-UAM.

Edited by: P. F. Biagi

Reviewed by: two anonymous referees

\section{References}

Bernard, P.: Plausibility of long distance electrotelluric precursors to earthquakes, J. Geophys. Res., 97, 17 531-17 596, 1992.

Eftaxias, K., Kapiris, P., Polygiannakis, J., Kopanas, J., Peratzakis, A., Skountzos, P., and Jaggard, D.: Review and a model of pre-peismic electromagnetic emissions in terms of fractal electrodynamics, Fractals, 12, 243-273, 2004.

Flores-Márquez, E. L., Márquez Cruz, J., Ramírez-Rojas, A., Gálvez-Coyt, G., and Angulo-Brown, F.: A statistical analysis of electric self-potential time series associated to two 1993 earthquakes in México, Nat. Hazard Earth Sys., 7, 549-556, 2007.

Fraser-Smith, A. C., Bernardi, A., McGill, P. R., Ladd, M. E., Helliwell, R. A., and Villard Jr., O. G.: Low-frequency magnetic field measurements near the epicenter of the Ms 7.1 Loma Prieta earthquake, Geophys. Res. Lett., 17, 1465-1468, 1990.

Gotoh, K., Hayakawa, M., Smirnova, N. A., and Hattori, K.: Fractal analysis of seismogenic ULF emissions, Phys. Chem. Earth, 29, 419-424, 2004.

Hayakawa, M., Kawate, R., Molchanov, O. A., and Yumoto, K.: Results of ultra-low-frequency magnetic field measurements during the Guam earthquake of 8 August 1993, Geophys. Res. Lett., 23, 241-244, 1996.

Hayakawa, M., Ito, T., and Smirnova, N.: Fractal analysis of ULF geomagnetic data associated with the Guam earthquake on $8 \mathrm{Au}-$ gust 1993, Geophys Res. Lett., 26, 2797-2800, 1999.
Hayakawa, M., Ito, T., Hattori, K., and Yumoto, K.: ULF electromagnetic precursors for an earthquake at Biak, Indonesia on 17 February 1996, Geophys. Res. Lett., 27, 1531-1534, 2000.

Hayakawa, M.: NASDA's Earthquake Remote Sensing Frontier Research, Seismo-electromagnetic Phenomena in the Lithosphere, Atmosphere and Ionosphere, Final Report, Univ. of ElectroCommunications, March, 228, 2001. Nat. Hazard Earth Sys., 1, 119126, 2001.

Hayakawa, M., Molchanov, O. A., and NASDA/UEC Team: Summary report of NASDA's Earthquake Remote Sensing Frontier Project, in: Special Issue on Seismo Electromagnetic and Related Phenomena, edited by: Hayakawa, M., Molchanov, O. A., Biagi, P. F., and Vallianatos, F., Phys. Chem. Earth, 29, 4-9, 617626, 2004.

Hayakawa, M., Hattori, K., and Ohta, K.: Monitoring of ULF (ultralow-frequency) geomagnetic variations associated with earthquakes, Sensors, 7, 1108-1122, 2007.

Higuchi, T.: Approach to an irregular time series on basis of the fractal theory, Physica D, 31, 277-283, 1988.

Higuchi, T.: Relationship between the fractal dimension and the power law index for a time series: A numerical investigation, Physica D, 46, 254-264, 1990.

Ida, Y., Hayakawa, M., Adalev, A., and Gotoh, K.: Multifractal analysis for the ULF geomagnetic data during the 1993 Guam earthquake, Nonlinear Proc. Geoph., 12, 157-162, 2005.

Ida, Y., and Hayakawa, M.: Fractal analysis for the ULF data during the 1993 Guam earthquake to study prefracture criticality, Nonlinear Proc. Geoph., 13, 409-412, 2006.

Ida, Y., Hayakawa, M., and Timashev, S.: Application of different signal analysis methods to the ULF data for the 1993 Guam earthquake, Nat. Hazard Earth Sys., 7, 479-484, 2007.

Kopytenko, Y. A., Matishvili, T. G., Voronov, P. M., Kopytenko, E. A., and Molchanov, O. A.: Detection of ultra-low-frequency emissions connected with the Spitak earthquake and its aftershock activity, based on geomagnetic pulsations data at Dusheti and Vatdzia observations, Phys. Earth Planet. Inter., 77, 85-95, 1993.

Kostopoulos, D., Varotsos, P., and Mourikis, S.: The conductivity of crystalline NaI, Can. J. Phys. 53, 1318-1320, 1975.

Lazaridou, M., Varotsos, C., Alexopoulos, K., and Varotsos, P.: Point defect parameters of LiF, J. Phys. Chem., Solid State, 18, 3891-3895, 1985.

Molchanov, O. A., Kopytenko, Y. A., Voronov, P. M., Kopytenko, E. A., Matiashvill, T. G., Fraser-Smith, A. C., and Bernardi, A.: Results of ULF magnetic field measurements near the epicenters of the Spitak $(\mathrm{Ms}=6.9)$ and Loma Prieta $(\mathrm{Ms}=7.1)$ earthquakes: Comparative analysis, Geophys. Res. Lett., 19, 14951498, 1992.

Peng, C.-K., Buldyrev, S. V., Havlin, S., Simons, M., Stanley, H. E., and Goldberger, A. L.: Mosaic organization of DNA nucleotides, Phys. Rev. E 49, 1685, 1994.

Peng, C.-K., Havlin, S., Stanley, H. E., and Goldberger, A. L.: Quantification of scaling exponents and crossover phenomena in nonstationary heartbeat time series, Chaos, 5, 1, 82-87, 1995. 
Ramirez-Rojas, A., Pavia-Miller, C. G., and Angulo-Brown, F.: Statistical behavior of the spectral exponent and the correlation time of electric self-potential time series associated to the Ms=7.4 14 September 1995 eqrthquake in Mexico, Phys. Chem. Earth, 29, 305-312, 2004.

Smirnova, N., Hayakawa, M., Gotoh, K., and Volobuev, D., Scaling characteristics of ULF geomagnetic field at the Guam seismoactive area and their dymanics in relation to the earthquake, Nat. Hazard Earth Sys., 1, 119-126, 2001.

Smirnova, N., Hayakawa, M., and Gotoh, K.: Precursory behavior of fractal characteristics of the ULF electromagnetic fields in seismic active zones before strong earthquakes, Phys. Chem. Earth, 29, 445-451, 2004.

Telesca, L., Cuomo, V., Lapenna, V., and Macchiato, M.: A new approach to investigate the correlation between the geoelectrical time fluctuations and earthquakes in a seismic area of southern Italy, Geophys. Res. Lett., 28, 4375-4378, 2001.

Telesca L., Colangelo, G., Lapenna, V. and Macchiato M., Monofractal and multifractal characterization of geoelectrical signals measured in southerm Italy, Chaos Soliton. Frac., 18, 385-399, 2003.

Telesca L., Colangelo, G., Lapenna, V.: Multifractal variability in geoelectrical signals and correlation with seismicity: a study case in southerm Italy, Nat. Hazard Earth Sys., 5, 673-677, 2005 a.

Telesca L., Lapenna, V., and Macchiato, M.: Multifractal fluctuation in earthquake related geoelectrical signals, New J. Phys., 7, 214, doi:10.1088/1367-2630/7/1/214, 2005b.

Telesca, L., Balasco, M., and Lapenna, V.: Investigating the time correlation properties in self-potential signals recorded in a seismic area of Irpinia, southern Italy, Chaos Soliton. Frac., 32, 199211, 2007.

Uyeda, S. T., Nagao, Y., Orihara, T., Yamaguchi, and Takahashi I.: Geoelectric potential changes: Possible precursors to earthquakes in Japan, Proc. Nat. Ac. Sc. (PNAS) 97-9, 4561-4566, 2000.
Varotsos, P. A.: An estimate of the pressure dependence of the dielectric constant in alkali halides, Phys. Status Solidi B, 90, 339 343, 1978.

Varotsos, P. A.: Determination of the dielectric constant of alkali halide mixed crystals, Phys. Status Solidi B, 100, K133-138, 1980.

Varotsos, P. and Alexopoulos, K.: Negative activation volumes of defects in solids, Phys. Rev. B, 21, 4898-4899, 1980.

Varotsos, P. and Alexopoulos, K.: Physical properties in the variation of the electric field of the Earth preceding earthquakes, I. Tectonophysics, 110, 73-98, 1984a.

Varotsos, P. and Alexopoulos, K.: Physical properties in the variation of the electric field of the Earth preceding earthquakes, II. Tectonophysics, 110, 99-125, 1984b.

Varotsos, P. A., Lazaridou, M., Eftaxias, K., Antonopoulos, G, Makrris, J., and Kopanas, J.: Short term earthquake prediction in Greece by seismic electric signals, in: A critical Review of VAN, edited by: Sir James Lighthill, World Scientific, 29-76, 1996.

Varotsos, P. A., Sarlis, N. V., and Skordas, E. S.: Long-range correlations in the electric signals that precede rupture, Phys. Rev. E, 66, 011902, 2002.

Varotsos, P. A., Sarlis, N. V. and Skordas, E. S.: Attempt to distinguish electric signals of a dichotomous nature, Phys. Rev. E, 68, 031106, 2003.

Varotsos, P. A.: The Physics of Seismic Electric Signals, TerraPub, Tokyo, 338 pp., 2005.

Yépez, E., Angulo-Brown, F., Peralta, J. A., Pavía-Miller, C. G. and González-Santos, G.: Electric fields patterns as seismic precursors, Geophys. Res. Lett., 22, 3087-3091, 1995.

Yonaiguchi, N., Ida, Y., Hayakawa, M., and Masuda, S.: A comparison of different fractal analyses for VHF electromagnetic emissions and their self-organization for the off-sea Miyagiprefecture earthquake, Nat. Hazard Earth Sys., 7, 485-493, 2007. 